\title{
HADIS-HADIS TENTANG PENDIDIKAN (Suatu Telaah tentang Pentingnya Pendidikan Anak)
}

\author{
Susan Noor Farida \\ Anggota Persistri Kota Bandung, Jawa Barat, Indonesia \\ E-Mail: Susannoor@gmail.com
}

\begin{abstract}
It is very important in shaping the nature and character of man to be perfect man is education. Through education, be it family, school, or neighborhood, people can open mind for instance that there is nothing in the universe, there are a lot of science. From the start that there is in humanity itself up space that is difficult to reach by the senses and in the end thinking that the universe is the creator and owner.among the rule was one of a child's education should be noted that education in childhood that will affect the character of the child as an adult later. Education of children is not only done when they are still small. But, carried in the womb until he grew up. Hadith as part of the essential teachings of islam have so many precious cargo that can be used as a foothold in the education of children of this discourse. Therefore, the authors will describe some of the hadith related to the education of children.
\end{abstract}

Keywords: Child; Content; Education; Hadits; Mature.

\begin{abstract}
Abstrak
Hal Yang Sangat Penting Dalam Membentuk Sifat Dan Karakter Manusia Menjadi Insan Kamil Adalah Pendidikan. Melalui Pendidikan Baik Itu Keluarga, Sekolah, Ataupun Lingkungan Sekitar, Manusia Dapat Terbuka Fikirannya Bahwa Apa-Apa Yang Ada Dialam Semesta Ini Terdapat Banyak Sekali Ilmu. Dari Mulai Yang Ada Di Dalam Diri Manusia Itu Sendiri Hingga Luar Angkasa Yang Sulit Dijangkau Oleh Panca Indra Dan Pada Akhirnya Berfikir Bahwa Alam Semesta Adalah Pemilik Sang Pencipta Dan Dialah Yang Mengatur Segalanya

Diantara Aturan Itu Salah Satunya Tentang Pendidikan Anak Yang Harus Diperhatikan Bahwa Pendidikan Pada Masa Kanak-Kanaklah Yang Akan Berpengaruh Pada Karakter Anak Itu Ketika Telah Dewasa Nanti. Pendidikan Terhadap Anak Tidak Hanya Dilakukan Ketika Mereka Masih Kecil. Tapi, Dilakukan Sejak Dalam Kandungan Sampai Ia Tumbuh Dewasa.

Hadis Sebagai Bagian Dari Ajaran Penting Dalam Islam Memiliki Sekian Banyak Muatan Mulia Yang Bisa Dijadikan Pijakan Dalam Wacana Pendidikan Anak Ini. Oleh Karena Itu, Penulis Akan Menguraikan Beberapa Hadist Terkait Pendidikan Anak.
\end{abstract}

Kata Kunci: Anak; Hadis; Dewasa; Kandungan; Pendidikan.

\section{A. PENDAhuluan}

Dalam roh Islam terdapat tiga aspek penting, yaitu Iman-Islam-Ihsan, atau aqidahibadah-akhlak. Makna yang terkandung dalam ketiga aspek itu di dalamnya meliputi : atribut, substansi dan perilaku. Oleh karena itu beribadah itu sama dengan bertaqwa yang tidak hanya meliputi ibadah mahdhah saja tetapi juga ibadah sosial (mu'amalah), dan berakhlak tidak hanya meliputi sikap tetapi juga perilaku interaktif dan komunikatif. Maka beragama atau berIslam artinya berperilaku ekspresif, produktif, dan komunikatif sesuai dengan nilai dan norma Islam.
Sementara berperilaku hanya mungkin terjadi bila diawali oleh proses berpikir (melakukan penilaian) dan bersikap untuk memotivasi suatu perbuatan atau perilaku tertentu. "Kegiatan" terakhir ini merupakan komponen kultur atau peradaban manusia. Jadi, peradaban Islam itu sama artinya dengan berperilaku Islami. Munculnya perilaku yang Islami itu tentunya membutuhkan terlebih dahulu terjadinya proses aktualisasi diri masing-masing anggota masyarakat. Karena itu, untuk mengaktualkan dan mengkondisikan diri ke arah itu, maka disini dibutuhkan pendidikan. Itu sebabnya pendidikan Islam seperti dilihat dari sudut etimologi sering digunakan istilah 
ta'lim dan tarbiyah yang akar katanya berasal dari kata 'allama dan rabba yang dipergunakan dalam al-quran, sekalipun kata tarbiyah lebih luas konotasinya yaitu mengandung arti memlihara, membesarkan dan mendidik yang sekaligus mengandung makna mengajar ('allama).

Prof. Dr. Naqib Alatas, ${ }^{1}$ dalam bukunya Islam dan secularism mengajukan istilah lain yaitu ta'dib yang ada hubungannya dengan kata adab yang berarti susunan. Dia berpendapat bahwa mendidik tiada lain adalah membentuk manusia untuk menempati tempatnya yang tepat dalam susunan masyarakat, berperilaku secara proporsional sesuai dengan ilmu yang dikuasainya. Mendidik juga berkonotasi bahwa si pendidik harus mampu menyampaikan masing-masing ilmu atau hubungan ilmu dengan ilmu yang lain dalam satu susunan yang sistemik dan harus disampaikan sesuai dengan kemampuan dasar (competence) yang dimiliki peserta didik dan kemudian melalui teknologi dan keterampilan tertentu diaplikasikan dalam suatu keteraturan perangkat sistem sehingga memungkinkan untuk menjadi alat yang ampuh bagi kehidupan manusia dalam membentuk dan mengembangkan masyarakatnya beserta budayanya dalam suatu kontinum yang terus menerus berproses menuju tingkat kesempurnaan tertentu.

Itu sebabnya, tujuan pendidikan Islam dalam pandangan para ahli, sekurangkurangnya ditujukan untuk mampu membentuk dan mengembangkan manusia muslim yang minimal menguasai ibadah mahdhah, dan secara maksimal mampu membentuk dan mengembangkan ahli-ahli ilmu agama Islam dengan segala aspeknya.

Demikian pula fungsi pendidikan Islam yang bertitik tolak dari prinsip iman-Islamihsan dan atau aqidah-ibadah-akhlak adalah untuk menuju suatu sasaran kemuliaan manusia dan budaya yang diridhai oleh Allah SWT., yang setidak-tidaknya memiliki fungsi secara minimal individuasi nilai dan ajaran

\footnotetext{
${ }^{1}$ Yusuf A. Feisal, Makalah: Pokok-Pokok tentang Ilmu Pengetahuan Islam, (Bandung: Yayasan Ulul Albab, 1992), 9.
}

Islam demi terbentuknya manusia muttaqin, dan secara maksimal adalah sosialisasi nilainilai dan ajaran Islam demi terbentuknya umat Islam, serta rekayasa kultur Islam demi terbentuk dan berkembangnya peradaban Islam. $^{2}$

Dengan demikian terlihat bahwa pendidikan Islam merupakan rohnya peradaban Islam, yang sudah tentu Nabi sebagai pembawa risalah Allah SWT sangat berkepentingan dengan persoalan ini, setidaknya untuk memberikan poetunjuk bagi pertumbuhan pendidikan Islam, minimal dari segi prinsipnya yang mampu mendasari pendidikan itu sendiri, baik pada masa beliau hidup maupun sesudahnya. Karena itu dalam makalah ini, sesuai dengan judul di atas diusahakan untuk ditemukan sabda-sabda Nabi tersebut.

\section{B. PEMBAHASAN \\ 1. Takhrij Hadis}

Metode takhrij yang digunakan dalam penelitian ini adalah Takhrij al hadis bil lafz danTakhrij al hadis bil maudhu'. Adapun metode takhrij hadis bi lafz ada dua cara, yaitu:

1. Dengan cara mengetahui lafaz dari matan hadis

2. Dengan cara mengetahui lafaz matan hadis yang paling sedikit berlakunya

Dalam penelitian hadis bi lafz pelacakan materi hadis ini mencakup kata 'allimu, dharaba, al-shalah dan madja'un (jamak

: madaji') dan walada. Setelah dilihat langsung dalam kitab Mu'jam al Mufahraz li Alfazi al Hadis an Nabawi, penyusun mendapatkan hadis-hadis tersebut terdapat dalam kitab-kitab hadis yaitu Kitab Sunan Abi Daud, Sunan at Turmuzi, Sunan ad Darimi dan Musnad Ahmad bin Hanbal. Dari penelusuran hadis melalui metode ini didapattilah sekian banyak hadis yang tergabung dalam pembahasan tema berikut.

\footnotetext{
${ }^{2}$ Yusuf A. Feisal, Makalah: Pokok-Pokok tentang Ilmu Pengetahuan Islam, 11.
} 


\section{Pembicaraan Hadis tentang Prinsip- Prinsip Pendidikan}

Sebagaimana telah dijelaskan bahwa pendidikan dalam konsep Islam adalah memlihara, membesarkan dan mendidik yang sekaligus mengandung makna mengajar. Jadi, pendidikan itu adalah memberikan bimbingan secara sadar oleh pendidik terhadap perkembangan rasio dan mental atau jasmani dan rohani si terdidik menuju terbentuknya kepribadian yang utama.

Beberapa prinsip pendidikan seperti itu jika ditelusuri dari perkembangan Islam awal seperti yang ditunjuki oleh hadis Nabi, meski masih sangat umum, Nbai telah banyak membicarakannya. Misalnya beberapa prinsip dasar tentang mencari ilmu maupun petunjuk menyampaikan suatu ilmu yang merupakan bagian dari proses pendidikan itu antara lain temukan dalam hadis-hadis sebagai berikut:

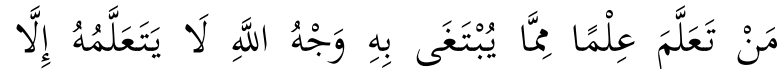

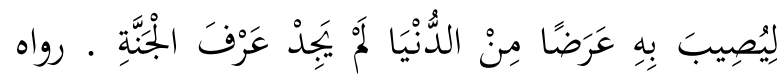

$$
\text { احمد وابوداودوابن ماجه. }
$$

"Barangsiapa mempelajari suatu ilmu yang tidak untuk mencari keridhan Allah, tapi hanya untuk mendapatkan nilai-nilai material dari kehidupan duniawi, maka ia tidak akan mencium harumnya surga." Riwayat Ahmad, Abu Dawud, dan Ibnu Majah.

Menurut penilaian Muhammad Ibn Shalih al-'Utsaimin, ${ }^{3}$ yang mengutip penilaian Nashir al-Din al-Albani hadis ini shahih, baik yang diriwayatkan oleh Abu Dawud, Ibn Majah, maupun oleh Ahmad. Dalam sunan Abu Dawud tercantum dalam hadis nomor 3664, dalam sunan Ibnu Majah tercantum dalam hadis nomor 252, dan dalam musnad Ahmad tercantum dalam II:238, dan lainlain, yang bersumber dari Abu Hurairah.

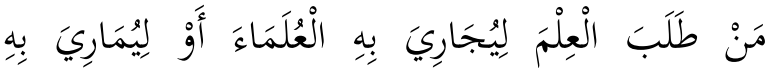

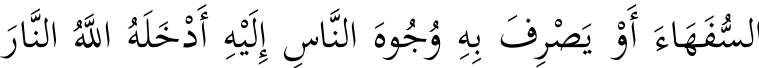

$$
\begin{aligned}
& \text { • رواه الترمذي }
\end{aligned}
$$

3 Musthalah al-Hadis, (Saudi Arabia: Darl AlFatah al-Syariqah, 1994), 123.
"Barangsiapa menuntut ilmu untuk menyaingi para ulama, atau untuk menyombongi orang-orang bodoh atau untuk memalingkan pandangan orang-orang kepadanya, maka Allah memasukkannya ke dalam neraka" Riwayat al-Tirmidzi.

Dalam pandangan Jalal al-Din al-Suyuthi, hadis yang bersumber dari periwayatan Ka'ab Ibn Malik ini kualitasnya hasan. Namun ada hadis lain yang berbeda redaksi dengannya, seperti hadis di bawah ini:

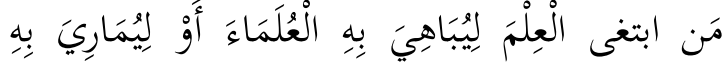

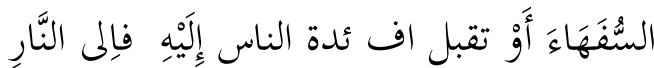

"Barangsiapa mencari ilmu untuk menyaingi para ulama, atau menyombongi orang-orang bodoh, atau agar hati orangorang mengarah kepadanya, maka ia menuju ke neraka" riwayat al-Hakim dan Thabrani dari Ka'ab Ibn Malik.

Menurut al-Suyuthi hadis yang kedua ini kualitasnya shahih. ${ }^{4}$ Jadi, meskipun kulaitas hadis pertama hasan, namun dikuatkan dengan hadis yang kedua ini yang berkualitas shahih, sehingga dari segi kehujjahan hadis tersebut dapat dijadikan hujjah. Ternyata pula hadis tersebut diriwayatkan pula oleh imam-imam hadis yang lain seperti altirmidzi dan ibn majah. ${ }^{5}$

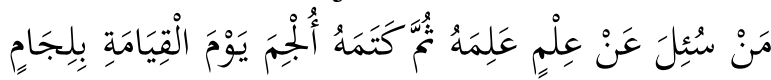

$$
\begin{aligned}
& \text { مِنْ نَارٍ رواه الترمذي }
\end{aligned}
$$

"Barangsiapa yang ditanya tentang suatu ilmu yang diketahuinya lalu ia menyembunyikannya, maka dia dikekang pada hari kiamat dengan kekang dari neraka." Riwayat Ahmad, Abu Dawud, dan al- Tirmidzi.

Menurut al-Suyuthi hadis ini adalah shahih. Hadis-hadis yang senada dengan hadis di atas banyak terdapat dalam kitabkitab hadis. Abu Dawud mencantumkannya

\footnotetext{
${ }^{4}$ Al-Suyuthi, Al-Jami' Al-Shaghir, diterjemahkan Oleh H. Nadjih Ahjad, (Surabaya: PT. Bina Ilmu, 1996), Jilid V, 9 dan 267.

${ }^{5}$ Sunan At-Tirmidzi, Hadis No. 2654, yang bersumber dari periwayatan Ka'ab Ibn Malik, Lihat pula Sunan Ibnu Majah, Hadis No. 260, yang bersumber dari Abu Hurairah. Menurut Nasr Al-Din al-Albani, Kualitas Hadis ini Hasan. Lihat Shahih alJami Hadis No. 6382-3
} 
dalam kitab sunannya pada hadis nomor 3658, dan sunan al-Tirmidzi hadis nomor 2649, dan Ibnu Majah hadis nomor 261 dan 266, dan musnad Ahmad, jilid II: 273, dan yang lainnya yang bersumber dari Abu Hurairah. ${ }^{6}$

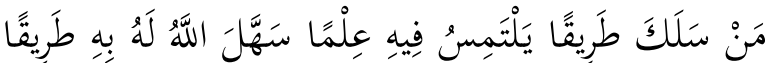

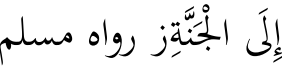

"Barangsiapa melewati suatu jalan untuk mencari ilmu, Allah memudahkan untuknya jalan ke surga" riwayat Muslim.

Menurut penelitian Jalal al-Din alSuyuthi, kualitas hadis ini hasan, seperti tercantum dalam kitabnya: al-Jami' alShagir min Hadis al- Basyir al-Nadzir, Jilid V. Namun menurut penelitian Muhammad Nashir al-Din al-Albani, kualitas hadis ini shahih, seperti tercantum dalam kitabnya: Shahih al-Jami al-Shagir wa Ziyadatih, jilid V hlm. 302. ${ }^{7}$

hadis ini tercatat dalam Shahih Muslim, hadis no. 2699, juga terdapat dalam sunan Abu Dawud hadis no. 3643, al-Tirmidzi hadis no. 2636, dan Ibn Majah hadis no. 225, yang bersumber dari Abu Hurairah.

Jadi, dari segi kualitas hadis ini dapat dijadikan hujjah. Bahkan Muhammad Ibn Shalih al-'Utsaimin ${ }^{8}$ seorang ulama hadis Saudi Arabia mengupas secara panjang lebar hadis ini, yang intinya ia menyatakan bahwa kesungguhan dalam mencari ilmu itu bisa beranugrah surga, dan itu merupakan hikmah bagi para pengabdi ilmu. Kemudian ia hubungkan dengan firman Allah: "Allah memberikan hikmah kepada siapa yang dikehendaki-Nya. Dan barangsiapa yang diberi hikmah, sungguh telah diberi kebaikan yang banyak. Dan tak ada yang dapat mengambil pelajaran kecuali orang-orang yang berakal" (QS. Al-Baqarah: 269).

\section{Pembicaraan Hadis tentang Pentingnya \\ Pendidikan Anak Sejak Dini}

Tema-tema pendidikan yang lebih spesifik lagi bila dibandingkan dengan tema Hadis yang dikemukakan sebelumnya, adalah tentang pendidikan anak. Namun tema ini

\footnotetext{
${ }^{6} \mathrm{Al}$-Suyuthi, Al-Jami' Al-Shaghir, 236.

${ }^{7}$ Al-Suyuthi, Al-Jami' Al-Shaghir, 243

${ }^{8}$ Musthalah al-Hadis, 127.
}

pun masih bersifat gagasan umum. Hal ini bisa dimengerti karena kondisi sosial pada masa awal Islam masih belum disadari arti pentingnya pendidikan itu. Pembicaraan hadis tentang pendidikan anak yang dimaksud, misalnya hadis di bawah ini.

$$
\begin{aligned}
& \text { كُلُّ مَوْلُودٍ يُوَلَدُ عَلَى الْفِطرَة حى يعرب عنه لسانه }
\end{aligned}
$$

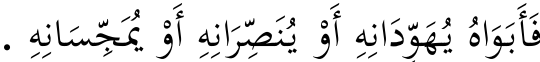
menerangkan maksudnya, kemudian orangtuanya yang membuatnya jadi Yahudi, Nasrani, atau Majusi" Riwayat Abu Ya'la, al-thabrani, dan al-Baihaqi, dari Aswad ibn Sari.

Menurut penelitian al-Suyuthi, kualitas hadis ini adalah shahih. ${ }^{9}$ Dengan demikian hadis ini dapat dijadikan hujjah. Karenanya, berdasarkan petunjuk hadis ini peran sentral orang tua dalam pendidikan anak sangat menentukan bagi suksesnya pendidikan anak.

Petunjuk hadis di atas, jika dikaitkan dengan kajian keilmuan kontemporer, misalnya ilmu Psikologi, akan bertautan dan saling menguatkan. Misalnya, menurut psikologi, anak pada dasarnya dipengaruhi oleh dua faktor yang terintegrasi yaitu pembawaan dan lingkungan. Sementara menurut hadis di atas ditegaskan bahwa anak sangat dipengaruhi oleh lingkungan keluarga terutama pihak orangtuanya. Di sini faktor pembawaan atau watak anak yang diturunkan oleh orangtuanya itu sebenarnya sudah tercakup. Namun demikian, dalam kajian Islam bahwa faktor-faktor pembawaan maupun maupun faktor-faktor dari luar kedua-duanya dapat berpengaruh pada anak yang sedang tumbuh dan berkembang.

Pengakuan Islam terhadap adanya faktor keturunan ini dibuktikan dengan sabda Nabi yang menyatakan sebagai berikut.

$$
\text { تَخَيَرَو الِنُطَفِكُمْ فان العرق دساس . . . }
$$

"Pilihlah olehmu tempat penumbuhan nutfahmu, karena darah itu mengalir terus..." Riwayat al-Nasai. ${ }^{10}$

Hadis yang serupa dengannya antara lain :

\footnotetext{
${ }^{9}$ Al-Suyuthi, Al-Jami' Al-Shaghir, 117-118

${ }^{10}$ Ali Fikry, al-Ihsan, (Beirut: Dar al-Fikr, tt), 97.
} 


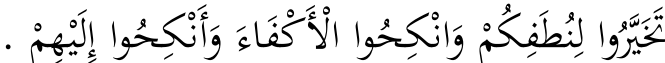

"Pilihlah (perempuan) untuk nutfahmu, lalu kawinilah perempuan-perempuan yang setingkat dan gaulilah mereka" Riwayat Ibn Majah, Hakim, dan Baihaqi. Menurut penilaian al-Suyuthi hadis ini berasal dari periwayatan Aisyah dan kualitasnya shahih. ${ }^{11}$

Hadis yang lain bahkan memperingatkan agar berhati-hati memilih calon istri (demikian pula calon suami), karena watak orangtuan itu akan menurun kepada anak. Hal ini sebagaimana dinyatakan:

$$
\begin{aligned}
& \text { اياكم وحضراءالدمن فقالواوماوحضراءالدمن يارسول } \\
& \text { الله ؟ قال : المراة الحسناءفى المنبت الوء السوء }
\end{aligned}
$$

"Hati-hatilah terhadap tumbuh-tumbuhan hijau yang tumbuh di tempat yang kotor. Kemudian para shahabat bertanya : apakah yang dimaksud dengan tumbuh-tumbuhan hijau di tempat yang kotor itu, wahai Rasulullah? Nabi menjawab: yaitu wanita cantik tapi tumbuh (besar) di tempat yang jelek..."12

Bahkan al-quran membicarakan pula tentang pengaruh keturunan dalam proses kejadian, pertumbuhan dan perkembangan anak. Al-quran mengisahkan bagaimana Allah mengutamakan keluarga Ibrahim dari sekalian alam sebagai hasil dari keturunan yang saleh yang terus turun pada generasi berikutnya. ${ }^{13}$

Nabi Nuh mendoakan bagi kebinasaan kaumnya yang kafir itu, karena mereka tidak memberi keturunan kecuali orang kafir. "Nuh berkata: Ya Tuhanku! Janganlah Engkau biarkan seorang pun diantara orang-orang kafir itu tinggal di bumi. Sesungguhnya jika Engkau biarkan mereka tinggal, niscaya mereka akan menyesatkan hamba-hambaMu, dan mereka tidak akan melahirkan selain anak yang berbuat maksiat yang sangat kafir" (QS. Nuh: 26-27).

\footnotetext{
${ }^{11}$ Al-Suyuthi, Al-Jami' Al-Shaghir, Jilid II, 343

12 Mohammad Jad al-Mawla, al-Khuluq al-Kamil, (Kairo: al-Maktabah, 1971), 104. (Penulisnya tidak menjelaskan Hadis ini diriwayatkan oleh siapa, dan tidak dijelaskan pula kualitasnya. Namun tampaknya Mohammad Jad al-Mawla mengakui bahwa hadis ini sebagai Hadios Shahih. Pen, ).

${ }^{13}$ Lihat Surat Ali Imran: 34.
}

Aliran konvergensi dalam psikologi mengakui adanya faktor yang berpengaruh yakni pengaruh dari dalam (pembawaan/keturunan) dan pengaruh dari luar (lingkungan) terhadap pertumbuhan dan perkembangan anak. ${ }^{14}$

Itu sebabnya, jika dilihat lebih jauh hadis yang menyatakan bahwa, semua anak yang dilahrikan itu akan sangat dipengaruhi oleh kedua orangtuanya, ajaran ini sesungguhnya mengilhami bagi pentingnya pentaan lingkungan keluarga untuk perkembangan anak. Karena faktor lingkungan termasuk lingkungan keluarga adalah salah satu faktor yang selalu ikut mewarnai dalam proses pertumbuhan dan perkembangan anak, apalagi setelah anak mulai dapat mengenal alam sekitarnya sehingga di sini sudah sangat terasa sekali adanya interaksi dan berbaur dari proses pertumbuhan dan perkembangan anak.

Agar lingkungan ini diharapkan agar dapat memberikan pengaruh yang positif terhadap proses pertumbuhan dan perkembangan anak diperlukan upaya penataan yang sungguh-sungguh terutama yang bersifat agamis.

Seperti disinggung di muka, perkembangan seseorang berlangsung dalam situasi pertemuan antara dia dengan orang sekitarnya, khususnya dengan orangtuanya. Situasi pertemuan itu merupakan situasi saling mengarah dan -disadari atau tidakssaling mempengaruhi. Seorang anak yang masih reseptif itu yang hidup dan berkembang di tengah keluarganya berorientasi kepada mereka, menangkap dan menyerap pola pikir dan pola hidup mereka sepanjang daya tangkap dan daya serapnya menginternalisasi norma-norma yang berlaku dalam situasi keluarga tersebut.

Jika diamati secara seksama, betapa kelahiran anak dan keberadaan seorang anak di tengah mereka mengubah pola hidup dan pola pikir mereka. Pengarahan perhatian orangtua kepada anak-anak tidak sematamata untuk keadaannya serta kelangsungan

\footnotetext{
${ }^{14}$ Pembahasan lebih jauh tentang masalah ini, Lihat: Proyek Pengembangan Institusi Pendidikan Tinggi tentang: Dasar ilmu Pendidikan (Buku II A), (Jakarta: Depdikbud, 1983), 35-40.
} 
hidupnya saat ini, melainkan mereka telah pula mengantisipasi dan memperhitungkan kelangsungan hidup selanjutnya. Mereka mengahrapkan anak mereka kelak dapat melaksanakan tugas hidupnya sebagaimana mestinya, bahkan lebih baik dari apa yang sekarang mereka jalani. Tidak jarang pula mereka mengharapkan anak dapat meraih cita-cita hidup yang mereka sendiri tidak mampu mencapainya. Dari sini semua tampak bahwa pola pikir serta hidup mereka dikaitkan dengan keberadaan anak di tengah mereka.

Dalam situasi seperti itulah anak berkembang di tengah keluarganya, maka sebenarnya perkembangan anak dalam keluarganya itu dapat dipandang sebagai peristiwa yang menyangkut pula perkembangan hidup orangtuanya. Dengan perkataan lain, situasi kehidupan keluarga yang di dalamnya terdapat seorang anak, merupakan situasi yang diciptakan, dibina, dan dikembangkan bersama, merupkan situasi bersama yang dihayati secara bersama. Karena kedudukan orangtua memegang peranan yang lebih aktif -walau dalam artian tidak menghilangkan aktivitas anak-akan tetapi jelas pula bahwa dengan keberadaan anak itu di tengah keluarganya, mengurangi pula kebebasannya untuk berbuat menurut kemauan dan kepentingan sendiri.

Dalam menghadapi anaknya, dengan memperhatikan kehidupan dan aktivitas anak serta masa depannya di saat anak tersebut dewasa yang berarti harus dapat mandiri dan bertanggung jawab sendiri dalam melaksanakan tugas hidupnya, maka orangtua di samping memberikan arahan secara tegas kepada anak, harus pula memberikan kesempatan kepadanya untuk belajar berbuat sendiri, dan anak pada dasarnya memiliki potensi untuk dapat aktif dan berbuat sendiri.

Dengan demikian baik orangtua maupun anka pada dasarnya ada pada situasi yang bipoler. Artinya bagi orangtua ia mngehadapi persoalan seberapa jauh ia harus dengan jelas membimbing dan memberikan arahan kepada anaknya dan seberapa jauh ia harus memberikan kesempatan kepada anak untuk berbuat sendiri.sedangkan di pihak anak situasi bipoler itu menyangkut persoalan seberapa jauh ia harus mengikuti dan mempercayakan diri kepada orangtuanya dan melaksanakan keinginannya sendiri. Jadi situasi bipoler ini menyangkut masalah kebebasaan dan keterikatan yang dihadapi baik oleh orangtua maupun anak.

Dalam pola pikir seperti ini tampaklah bahwa situasi keluarga tempat anak itu berada tidak sepenuhnya ditentukan, digariskan, atau dikonstruksi oleh orangtua ataupun anak, melainkan tersusun karena pola interaksi antara kedua belah pihak itu.

Sebab itu keberadaan bersama orang lain dalam situasi bersama membentangkan bagi anak suatu ruang yang dapat dimasukinya yang memungkinkannya mengembangkan diri sebagai manusia. Orangtua yang bagi anak lebih besar dan lebih tua merupakan representasi dari masa depannya. Artinya pada orangtua "yang lebih tua" itu belajar mengenal bagaimana berada sebagai orang yang telah besar, sebagai orang dewasa. Dengan mengamati dan hidup bersama orangtua, anak memproyeksikan diri dan mendapatkan gambaran tentang dirinya kelak; anak sepertinya bercermin pada orangtuanya.

Keadaan yang relatif lebih kurang dari keberadaan orangtuanya melahirkan pada diri anak suatu perasaan kecil yang berhadapan dengan orang besar yang serba tahu dan serba dapat, bahkan serba kuasa. Perlakuan yang penuh kasih sayang dari orangtua mengundangnya untuk mempercayakan diri dan mengikuti bimbingan dan arahannya.

Orangtua yang memandang anaknya sebagai amanat yang dipercayakan kepadanya untuk dibimbing dan dididiknya, dalam menghadapi anak tidak akan bersikap diam atau acuh. Ia akan sengaja dan sungguh-sungguh berupaya untuk melaksanakan tugas dan tanggungjawabnya sebagai orangtua; ada kalanya upayanya ini dengan cara yang tegas dan tandas dijelaskan kepada anak, berupa tindakan yang diambilnya terhadapnya, ada kalanya pula upaya tersebut tersirat dalam perilaku serta ucapannya sehari-hari, ada kalanya pula dalam cara menata dan menampilkan dirinya 
dalam situasi kebersamaan dengan anaknya itu. Yang terakhir ini dilakukan dengan menciptakan dan menata situasi ataupun iklim yang selaras dengan tujuan yang hendak dicapai oleh orangtuanya.

\section{SIMPULAN}

Dari uraian di atas, penulis berkesimpulan bahwa Kullu mawluddin Yuladu 'ala alfitrah... itu mengisyaratkan bagi pentinganya penataan iklim agamis di lingkungan keluarga, dan iklim-iklim positif lainnya. Karena lingkungan rumah merupakan proses awal bagi pertumbuhan anak. Itu sebabnya rumah merupakan lingkungan pendidikan bagi anak prasekolah. Seluruh iklim yang positif bagi perkembangan anak dibutuhkan di lingkungan prasekolah ini. Namun iklim agamis tampaknya harus mendapat prioritas utama, agar mampu memunculkan perilaku religius pada anak. Karena penciptaan generasi yang saleh lebih penting dari yang lainnya. Perjuangan Nabi Nuh 'alaihi salam, diakhiri dengan adzab air bah, karena ternyata di lingkungan keluarganya ada anak yang tidak taat kepada orangtuanya.
Sementara perjuangan Nabi Ibrahim 'alaihi salam berjalan mulus dan berhasil, sebab anaknya semuanya saleh, imannya dibuktikan dengan amal perbuatannya. Allah a'lam.

\section{DAFTAR PUSTAKA}

Feisal, Yusuf A. Makalah: Pokok-Pokok tenatang Ilmu Pengetahuan Islam, Bandung: Yayasan Ulul Albab, 1992.

Musthalah al-Hadis, Saudi Arabia: Darl AlFatah al-Syariqah, 1994.

Suyuthi, Abdurrahman bin Kamaluddin Abu Bakr bin Muhammad bin Sabiquddin, Jalaluddin al-Misri al-. Al-Jami' AlShaghir, diterjemahkan Oleh H. Nadjih Ahjad, Surabaya: PT. Bina Ilmu, 1996.

Sunan At-Tirmidzi, Sunan Ibnu Majah, Hadis No. 260

Fikry, Ali. al-Ihsan, Bairut: Dar al-Fikr, t.t.

Mawla, Mohammad Jad al-. al-Khuluq alKamil. Kairo al-Maktabah, 1971.

Proyek Pengembangan Institusi Pendidikan Tinggi tentang: Dasar ilmu Pendidikan (Buku II A), Jakarta: Depdikbud, 1983. 
Halaman ini sengaja dikosongkan 